УДК: 321; 123.

ДАХИН Андрей Васильевич - доктор философских наук, профессор; заведующий кафедрой философии и политологии Нижегородского института управления - филиала Российской академии народного хозяйства и государственной службы при Президенте РФ (603950, Россия, г. Нижний Новгород, nр-кт Гагарина, 46; kaf-phyl@niu.ranера.ru)

СОЛОНЧЕНКО Елизавета Игоревна - аспирант кафедры философии и политологии Нижегородского института управления - филиала Российской академии народного хозяйства и государственной службы при Президенте РФ (603950, Россия, г. Нижний Новгород, np-кт Гагарина, 46; kafphyl@niu.ranepa.ru

\title{
ГОРОДСКАЯ ПОЛИТИКА: КРИТИЧЕСКИЙ АНАЛИЗ ТЕОРЕТИЧЕСКИХ ПОДХОДОВ
}

\begin{abstract}
Аннотация. Статья посвящена анализу современных отечественных и зарубежных теоретических подходов к исследованию городской политики. Выделяются 5 основных подходов - как традиционно свойственных политическим наукам, так и отражающих деполитизированное видение жизни города. Основное внимание уделено оригинальной концепции «интегрального города» М. Хэмилтон, отнесенной нами к полю деполитизированных. В статье показано, что концепция «интегрального города» представляет собой попытку соединения философского системного понимания города и эмпирического его описания. Рассмотрение основных философских определений и рассуждений концепции «интегрального города» позволяет сделать вывод, что философская платформа интегрирует человека в абстрактную систему «холонов». С другой стороны, «интегральный город» по умолчанию обладает политической миссией: он рассматривается М. Хэмилтон как система принуждения людей к исполнению природного «алгоритма выживания». В заключение сделан вывод о важности критического переосмысления основных философских аксиом концепции «интегрального города», а также о необходимости более точного определения системы политического управления, которую предполагает данный концепт.

Ключевые слова: городская политика, интегральный город, философия города, социальная идентичность, бионический постмодернизм
\end{abstract}

$\mathrm{P}$ азвитие городов и городская политика в России после 2010 г. стали предметом фокусированного внимания как реальной политики, так и социальнополитических, урбанистических исследований. Причины активного интереса политиков объясняются стартом ряда реформ системы городского политического управления (переход от постсоветской «одноглавой» модели управления муниципалитетом к «двуглавой», а затем - к новой «одноглавой» модели), реорганизации системы управления территориями на уровне муниципалитетов (укрупнение муниципальных образований, преобразование «районов области» в «муниципальные округа») и др. В этих условиях обостряются задачи выбора приоритетов городского развития, задачи стратегирования, задачи синхронизации целей государственных целевых программ с предпочтениями и интересами жителей городов и др. Городская социально-политическая активность привлекает политических аналитиков и урбанистов, которые тестируют привычные теоретические концепты и разрабатывают новые теоретические подходы. Международный фон городских социально-политических исследований также держится на достаточно высоком уровне активности, формирует обширную глобальную библиотеку, материалами которой активно пользуются российские исследователи. Поэтому анализ концептуальных, теоретических ресурсов наук, изучающих практики политического управления городами и городским развитием, - это актуальное направление научной деятельности, которое позволяет провести «сортировку», сделать отбор наиболее продуктивных концепций. 


\section{Теоретические подходы}

В русле российской политической науки наметилось несколько теоретических подходов к исследованию городской политики. Одни исследователи анализируют ее как элемент регионального политического процесса, в основном со стороны партийно-политической инфраструктуры, политической элиты, с опорой на понятие и методологию базового политического процесса [Авдонин 2013; Баранов 2011; Бирюков, Барсуков 2013; Дахин, Распопов 1998]. Вторые выделяют муниципальную политику в качестве самостоятельного направления политических исследований, делая при этом акцент на понятии «локальная», или «муниципальная», а не на понятии «городская» [Туровский 2015]. Третьи используют понятие «градополитика», в свете которого эмпирически исследуют градостроительные тенденции [Колхас 2015], практики городских общественных инициатив, движений, сообществ, которые являются частью городской публичной политики (В.Л. Глазычев, О.И. Генисаретский и др.). При наличии богатого эмпирического материала эти источники не содержат финальную концептуализацию, которая могла бы быть «зачтена» политической наукой. Концептуальное политологическое наполнение эти подходы получают в работах В.Г. Ледяева [Ледяев 2015]. Четвертые делают акцент на внедрение в отечественную политологическую рефлексию городской/муниципальной политики западных методологий и методов исследования [Авдонин 2006; Гельман 2008а; 2008б; Сравнительный регионализм ... 1997]. В основе лежат западные практики региональной стратификации, где фигурируют как городские (industrial), так и сельскохозяйственные (rural) политические пространства/тела. Западная региональная политическая стратификация исторически и практически строится «снизу». Город, городское сообщество здесь первично, а иное, субнациональное (земля в Германии, штат в США, кантон в Швеции и пр.), - вторично. В России система региональной стратификации строится «сверху», а потому здесь возможны эксперименты с «растворением» городского самоуправления в административно-территориальной организующей системе субъекта федерации, что является сугубо отечественной практикой.

Оценка современной политологии профессора Л.В. Сморгунова побуждает к выделению еще одного подхода. В коллективной монографии, посвященной анализу состояния российской политической науки, он пишет: «...современная политическая наука должна быть одновременно философской, сравнительной и практикоориентированной» [Сморгунов 2015: 8]. Перечисленные выше подходы не имеют содержательно развернутого философского компонента. Поэтому мы выделяем пятый подход, который предпринимает попытку соединения «философского» и «эмпирического» применительно к городскому развитию, но предлагает внешне деполитизированный дискурс о нем, очищая пространство города от всего политического с помощью метафор «системы», или «улья» [Хэмилтон 2013].

В поле региональной стратификации общества город занимает вполне устойчивое положение [Дахин 2015]. В классической научной традиции фундаментальный статус города обоснован в работах М. Вебера. Он рассматривает город как особенную разновидность поселения, а в качестве первоосновы города видит людей и людские сообщества [Вебер 1994]. В современных исследованиях идея исключительности и основательности миссии города представлена в работе М. Хэмилтон «Интегральный город». В отличие от Вебера, она ищет первоосновы городского существования и развития за пределами общественной природы. Этот подход получил достаточно широкую известность и популярность в среде российских городских активистов, стал частью публичного дискурса российского движения «живых городов». Как правило, это последо- 
ватели, апологетически относящиеся к идеям «интегрального города». Поэтому мы предпринимаем критический анализ этого оригинального концепта, в т.ч. и для того, чтобы уточнить смыслы его аполитичного дискурса.

\section{«Интегральный» город и природа}

В разделе «Предисловие: эволюционные размышления» автор представляет город в качестве центра переработки «материи, энергии и информации», который базируется на фундаменте глобальной природной и социальной эволюции: «Город - это наиболее концентрированная разновидность ареала обитания, созданного Hото sapiens sapiens» [Хэмилтон 2013: 31]. Значение города определяется не только его обращенностью на себя - «градоцентичностью», - но его обращенностью во все внешние среды/пространства: «Я утверждаю, - пишет Мерилин Хэмилтон, - что ценность города не заключается только в его ценности для выживания эгоцентрического индивида, не ограничивается она и ценностью принадлежности этноцентрическому коллективу или коллективам и даже ценностью экоцентрического устойчивого развития региона или нации. Эта метасистема координат интегрирует множество дисциплин, наук и искусств, чтобы переосмыслить город, как если бы он был целостной мироцентрической системой, которая поддерживает эволюцию человеческого сознания, сотрудничества и потенциальных способностей, вместе с тем добавляя ценность космоцентрической жизни на планете Земля» [Хэмилтон 2013: 36-37]. Этот тезис внешне созвучен идеям русского космизма, в т.ч. космизму ноосферному.

Неполитический город М. Хэмилтон, таким образом, вписан в материи физических, биологических, географических, геологических, виталистических и социокультурных систем, что и обеспечивает «интегральное» качество восприятия города. В этом прочитывается попытка обоснования фундаментальности города как природно-социального явления, которое могло бы быть вписано в «Коэволюцию» [Кутырев 1988] в качестве непрерывно пребывающей, динамичной, развивающейся, жизнеспособной (sustainable) локализованной в пространстве и времени субстанции. Безусловно, не всякий город обладает субстанциональной полнотой (есть города, которые исчезли, есть моногорода), но всякий город обладает субстанциональным потенциалом.

\section{«Холон» как метод интегрального мышления}

«“Интегральный город” - это способ рассмотрения города» [Хэмилтон 2013: 159], границы которого автор выбрала лично для себя [Хэмилтон 2013:104]. Она считает его правильным и предлагает читателю мыслить так же. Справедливо признавая «ценность мировоззрений и способов мышления», г-жа Хэмилтон излагает ключевые положения своего «интегрального» подхода, в контенте которых мы выделяем несколько смысловых слоев: 1) слой философско-методологический, 2) слой экономико-экологической рациональности и 3) слой эмпирически-антропологический. В поле первого слоя (здесь автор строит дорожную карту «принципов целостного мышления» [Хэмилтон 2013: 89]) город рассматривается как «диссипативная система» [Хэмилтон 2013: 101, 106], что замыкает данный подход на методологию синергетики с ее плюсами и минусами [Дахин 2009]. Соответственно, ключевыми «интегральными» понятиями становятся «фрактал», «система», «вложенные иерархии и фрактальные паттерны», «холон», «контейнер» и др. В частности, заимствованное из физики и биологии понятие «холон» используется в качестве маркера «целостной системы» [Хэмилтон 2013: 99, 464-465], так что в данном философско-методологическом измерении город представляет собой фрактальную систему холонов, которые 
горизонтально, по-соседски взаимодействуют друг с другом, вкладываются друг в друга, меняются и адаптируются, задавая и исчерпывающим образом объясняя «интегральную» динамику города [Хэмилтон 2013: 113, 147].

Редуцируя город к системе холонов, М. Хэмилтон обосновывает свое понимание города на позициях философско-методологического течения, в котором считается, что для решения задачи интеграции знания достаточно понятий «система» и «эмерджентность». Как система холонов, городская природа представляется как пустой сосуд - контейнер [Хэмилтон 2013: 103]: в него могут быть интегрированы материя, энергия, информация, а также люди. Поэтому город имеет и свои границы, и свою динамику [Хэмилтон 2013: 129], но его фундаментальная «интегральность» представляется как нечто отдельное (отделимое) от природного, технологического и человеческого наполнения, которое мы видим в городе [Хэмилтон 2013: 161-162]. Нарисованная «интегральная» система имеет универсальный характер и может быть приложена к различным объектам, в т.ч. к городу.

Второй и третий смысловые слои концепта «интегрального города» г-жи Хэмилтон связаны с расположенным в «контейнере» наполнением, где в перечне значатся четыре компонента («четырехсекторная карта») интегрального города: «субъективный» («я»), «межсубъективный» («мы/вы»), «объективный» («оно») и «межобъективный» («они») [Хэмилтон 2013: 181-182]. При этом предлагается переосмысление природы сознания. «Становится все более очевидно, - пишет М. Хэмилтон, - что сознание - это фундаментальное свойство Вселенной», а мы, люди, - «суть его выражения, имеющие способность быть ему свидетелями, проводниками и, возможно, даже теми, кто его расширяет» [Хэмилтон 2013: 264, 265]. «Интегральный город» как способ рассмотрения градополитики, таким образом, встраивает человека в глобальную экосреду.

Слой экономико-экологической рациональности представляет город как интегральную систему, которая находится в среде экорегиона, взаимодействует с ним, обменивается с ним материей, энергией, информацией [Хэмилтон 2013: 50]. Экорегион имеет определенную «несущую способность», которая ставит ограничения для развития (несомого им) города. На теле экорегиона город оставляет «экослед»: «Экологический след - это первая стадия в развитии подлинно базирующихся на природном капитале мониторов витальных признаков. Подсчет экоследа становится пробуждающим призывом для городов, которые измеряют свое ресурсопотребление и эквивалентное землеизмещение, чтобы понять степень, в которой они заимствуют природный капитал из непосредственного окружения и отдаленных геобиорегионов» [Хэмилтон 2013: 60]. На основе концепта экоследа строятся дальнейшие рассуждения М. Хэмилтон о городском ресурсопотреблении, о ресурсообороте/капиталообороте города и его экорегиона, об их эффективных и неэффективных формах: «Это означает, заключает автор «улья», - нахождение способов оптимизировать наше ресурсопотребление так, чтобы, как следствие, снизился уровень перегрева локальной и глобальной среды» [Хэмилтон 2013: 61]. Основной акцент делается на том, что система «город - экорегион» - это геобиологическая система. Она рассматривается как источник благополучия на климатическом, геологическом и биологическом уровнях. «Сколь бы сложным для подсчета ни оказался этот алгоритм выживания, мы не говорим о чем-то невозможном. Если живая разумная система, такая как пчелиный улей, способна понять, каким образом надо уравновешивать потребление и продуктивную способность Земли, тогда объективный урок состоит в том, что и человеческие системы на это способны» [Хэмилтон 2013: 62-63]. С опорой на принцип «уравновешивания потребления и продуктивной способности Земли» строятся рассуждения об экологичности и 
устойчивом развитии «интегрального города», вполне созвучные современным практикам повышения экологических стандартов в системах производства, перехода к использованию возобновляемых видов энергии и пр.

Третий смысловой слой работы «Интегральный город» - слой эмпирическиантропологический, - включает в поле зрения людское наполнение «контейнера». Ключевыми названы «личность», «значимые другие (семья, клан)» и «мир (общество, секторы труда, сферы влияния, регионы и планета)» [Хэмилтон 2013: 274], в среде которых наблюдаются «субъективные и межсубъективные реалии» [Хэмилтон 2013: 70, 182-183]. В комплексе характеризуется сфера социальной идентичности, в т.ч. локальной, связанной с местной мифологией, с местными легендами. Речь идет также о «ключевых центрах внутренних воззрений», о «внутренних реалиях» жителей города: «Несмотря на то что эти внутренние реалии жителей города в большинстве своем игнорировались или не рассматривались всерьез по причине своей незримости, субъективности и трудности для исследования, они столь же реальны, сколь и внешние физические реалии города. ‘...> Мы исследовали их сквозь призмы психологии, философии и гуманитарных дисциплин, однако до сих пор мы не признали тот факт, что, подобно нашим внешним качествам, они развиваются и эволюционируют», пишет г-жа Хэмилтон [Хэмилтон 2013: 69].

Природа человека, как это записано в главе, посвященной полю телесного поведения в городе, сводится к двум видам потребностей. Первая группа - поддерживающие нашу «биологическую реальность»: потребности в воздухе, воде и еде [Хэмилтон 2013: 77]. Вторая группа призвана «защищать и вмещать» нашу «биофизическую форму» (потребности в одежде и жилье) [Хэмилтон 2013: 188, 335] и учитывать «витальные факторы базового биофизического здоровья» [Хэмилтон 2013: 225]. Основная мысль сводится к тому, чтобы найти способы превратить эти «внутренние реалии» в готовность и желание людей «участвовать в поведении, направленном на обеспечение устойчивого развития» и на достижение «благополучной биологической жизни» в городе.

\section{«Интегральный город» и власть}

Приучить городское население к поведению, которое соответствовало бы экоприродному «алгоритму выживания» по примеру пчел, к новым критериям жизненности (адаптивность, регенерация) - вот что обеспечивало бы уравновешивание «потребления и продуктивную способность Земли». К этому сводится миссия «интегрального города». Распознавание значимости умонастроения и мировоззрения города сводится к тому, чтобы «оптимизировать жизнь в городе в контексте его природных литосферных и геобиологических ресурсов» [Хэмилтон 2013: 222]. В этом же состоит основной смысл стремления к построению города будущего, поскольку «интегральный город» рассматривается М. Хэмилтон в качестве идеального города будущего. Космоцентричная миссия человека заключается в том, чтобы осуществлять стандарт поведения, способный поддерживать баланс «потребления и продуктивной способности Земли», чтобы освоить «алгоритм выживания». При этом М. Хэмилтон утверждает: «Одна из ценностей коллектива состоит в том, что он выстраивает гибкость таким образом, что травма или потеря единичных холонов не приводит к потере целого улья». Сравнивая отдельного человека с клеткой многоклеточного организма, она пишет: «Жизненные условия изменяются только тогда, когда минимальная критическая масса клеток оказывается одновременно уничтожена или повреждена» [Хэмилтон 2013: 118]. Это означает, что городская эволюция не исключает травмирования или смерти отдельных людей в «интегральном 
городе». Город, таким образом, - это то, что может и должно принудить людей к этому режиму поведения.

Космоцентричное описание фундаментальности города раскрывает космическую фундаментальность его «интегральной» властной миссии: принудить Homo sapiens к тому, чтобы жить в гармонии с природой, заботиться об исполнении природного «алгоритма выживания». В книге говорится: «Те, кто находится у власти в данный момент, боятся принимать решения, которые не будут соответствовать общепринятым» социальным настроениям [Хэмилтон 2013: 221]. Поэтому, считает автор, городам суждено быть центрами принуждения людей к исполнению этого алгоритма «посредством массивной паутины информирующих взаимосвязей» [Хэмилтон 2013: 177]. Когда мы достигнем этой стадии, города будут цениться за тот вклад, который они вносят в благоустройство Земли и даже вселенной. Основной пункт, который является отражением политического поля жизни города, сводится к силе природного вселенского сознания, передатчиком которого выступает «интегральный город» - город-холон, который должен добиться от своих жителей (тоже холонов) правильного поведения путем мягкой или жесткой силы принуждения. «Интегральный город» представлен как системный инструмент принуждения Homo sapiens к тому, чтобы находиться в гармонии с природой, и в этом его космоисторическое, космоприродное предназначение. Образ деполитизированного «интегрального города» по умолчанию закрепляет за ним политическую миссию - функцию вселенского принуждения Homo sapiens sapiens к исполнению экологической миссии.

Содержание книги позволяет заключить, что свою властно-бионическую концепцию г-жа Хэмилтон продвигает в качестве альтернативы оруэлловским, бюрократическим подходам, создающим «большую сумятицу» [Хэмилтон 2013: 122, 218-219]. Противопоставление нового бионического старому механистическому/бюрократическому видению города вполне понятно. Однако предложенная взамен концепция бионической редукции деятельности человека к «алгоритму выживания» пчел требует критического рассмотрения.

Необходимо отметить, что теория «интегрального города» позволяет расширить видение политического поля городской жизни. Политологические концепции, отмеченные нами выше, ограничивают его, как правило, темами разделения властей, института выборов и активности политических партий, а также деятельностью различных акторов социально-политической стратификации (от «народа» до «элит») в политике. Концепт «интегрального города» делает акцент на том, что не социально-политическая, а биоприродная сила города предназначена для принуждения населения к определенному поведению, чем ставит новые вопросы. Прежде всего, это вопросы философии политического субъекта, вопросы «жестких» и «мягких» механизмов принуждения (насилия) в городе, вопросы роли системы образования в отработке задач «мягкого» принуждения в городе. Возникает также и вопрос комбинирования, гибридизации способов принуждения в городе, вопрос гибридных политик в городе. Перечисленные вопросы открывают новые перспективы политических исследований города.

\section{Заключение}

Безусловно, основными заслуживающими признания содержательными моментами подхода М. Хэмилтон являются:

- стремление утвердить видение города как целостной системы;

- утвердить важность природно-экологической составляющей человеческой деятельности в масштабе города; 
- соединить во взаимосвязанный комплекс философско-мировоззренческие знания о городе, с одной стороны, и узкоприкладные - с другой;

- утвердить принцип картирования и системной индикации городской жизни в качестве элемента публичной культуры и публичного диалога города;

- пробудить интерес жителей современного города к вопросу об образе города в желаемом будущем.

Однако то, как именно автор понимает выделенные стороны деятельности города, и то, какими смыслами она наделяет свои варианты содержательных рассуждений, вызывает не столько признательное, сколько критическое отношение. В частности, системное видение города полностью сводится к таким пустым означающим, как «фрактал», «паттерн» и «холон». В их незримо жесткие калибровки и цикличности с равной степенью послушания вливаются «биорегионы», «энергия», «люди», «материя», «информация», «пчелы» или «муравьи». Город, таким образом, деантропологизирован: получается, что это не человеческий, не антропомерный город, а космосистемный, ничейный город. Ради решения задачи «системного видения» г-жа Хэмилтон избавляется от человеческой «чейности» города. Чей же город по своей глубинной природе? На этот вопрос книга отвечает: «ничей, он вселенский» [Дахин 2019].

Наш вариант ответа на этот вопрос иной: город - это человеческий, антропомерный город. Поэтому глубинное системное видение города необходимо выводить из системного, целостного видения человека. Статусом системной первоосновы города обладает не холон, а человек. В понятном стремлении утвердить важность природно-экологической составляющей человеческой деятельности в масштабе города автор «интегрального города» также дает повод для основательной критики. Дело в том, что природно-экологический сегмент деятельности представлен в качестве высшей и конечной цели городской жизни. Человеку предлагается лечь в футляр «пчелиного» энергообмена с окружающей средой и считать это единственно достойной миссией своего пребывания на планете Земля и во вселенной. Сомнения нет, экологическим обезвреживанием современного города надо заниматься очень активно и последовательно. Но миссию бытия человека невозможно свести только к этому. Человек выпрямился из биологического мира природы, стал на «голову выше» мира растений и животных. Человек - это бытийно связанное с природой, но сущностно другое явление этого мира. Поэтому у человека должна быть определена еще и своя, человеческая миссия этом мире городов. Соответственно, у города также должна быть сугубо антропомерная миссия. В концепции г-жи Хэмилтон нет места этой проблематике. По умолчанию контент читается так, что никакой иной миссии, кроме как исполнять природный (пчелиный) завет «алгоритма выживания», нет и быть не может. Похвальное стремление соединить во взаимосвязанный комплекс философско-мировоззренческие и узкоприкладные знания о городе содержательно развернуто таким образом, что также требует критического переосмысления.

Критический анализ показывает, что на уровне философско-мировоззренческих посылок «интегральный город» г-жи Хэмилтон обосновывается на позициях бионического постмодернизма [Дахин 2019]. Автор противопоставляет его подход технократическому постмодернизму. Ее философия исключает понятие самотождественности и фундаментальной идентичности человека и общества в угоду «различению», она исключает «сущность» в угоду «эмерджентности», исключает «бытие» в угоду «взаимодействиям» и, наконец, в философии города исключает из первоначал «человека» в угоду «холонам».

В практической части концепции, в стремлении утвердить принцип картирования и системной индикации городской жизни в качестве элемента 
публичной культуры и публичного диалога города перечисленные недостатки философии «интегрального города» незаметны. В практической части вопросы городского управления, самоорганизации, обучения завязаны на поведение различных групп людей. Конкретные задачи городского развития не связываются с вопросами преобразования природы человека, основ бытия и пр. Конкретные решения нацелены на то, чтобы изменить массовое поведение горожан. Еще один вывод сводится к тому, что распространенные отечественные политологические подходы к градополитике требуют усиления связи с социально-философскими основаниями, со смыслами политической философии для того, чтобы более отчетливо конкурировать (или солидаризироваться) с такими философски фундированными подходами, один из которых представляет М. Хэмилтон.

\section{Список литературы}

Авдонин В.С. 2006. Развитие местного самоуправления в Германии и в России: История, проблемы, перспективы. - Политическая наука. № 3. С. 88-100.

Авдонин В.С. 2013. Рязанская область: «умеренный» авторитаризм становится жестче. - Политбук (Politbook). № 1. C. 59-78.

Баранов А.В. 2011. Понятие «Каспийский регион»: особенности понимания в новых условиях. - Региональные политические исследования. № 4. С. 5-12.

Бирюков С.В., Барсуков А.М. 2013. Региональные режимы правления в контексте теории султанизма. - Политбук (Politbook). № 1. C. 40-58.

Вебер М. 1994. Город. - Избранное. Образ общества. М.: Юрист. С. 309-446.

Гельман В. 2008а. Реформа власти в городах России: мэры, сити-менеджеры и местная демократия. - Сравнительное конституционное обозрение. № 6(67). C. 143-152.

Гельман В.Я. 2008б. Динамика субнацинального авторитаризма. Россия в сравнительной перспективе. СПб: М-Центр. 32 с.

Дахин А.В. 2009. Синергетическая парадигма: коррекция по проблеме исторического памятования. - Синергетическая парадигма. Социальная синергетика. М.: Прогресс-Традиция. С. 156-182.

Дахин А.В. 2015. Региональная стратификация общества: глобальное и локальное в культуре, экономике, и политике. Ч. 1. - Власть. № 10. С. 5-15.

Дахин А.В. 2019. «Интегральный город»: критический анализ теоретических подходов. - Вестник НИУ РАНХиГС: электронный научный журнал. Вып. 2. Доступ: http://services.niu.ranepa.ru/nauka/?page_id=8156 (проверено 27.10.2019).

Дахин А.В., Распопов Н.П. 1998. Проблема региональной стратификации в современной России. - Полис. Политические исследования. № 4. С. 132-144.

Колхас Р. 2015. Мусорное пространство. - Гигантизм, или Проблема Большого. Город-генерик. Мусорное пространство. М.: Арт Гид.

Кутырев В.А. 1988. Универсальный эволюционизм или коэволюция? Природа. № 8(876). С. 4-10.

Ледяев В.Г. 2015. Опыт изучения власти в городских сообществах: российская проекция. - Структурные трансформации и развитие отечественных школ политологии (под ред. О.В. Гаман-Голутвиной). М.: Аспект-Пресс. С. 59-78.

Сморгунов Л.В. 2015. Введение. - Российская политическая наука: Идеи, концепции, методы (науч. ред. Л.В. Сморгунов; под общ ред. О.В. ГаманГолутвиной). М.: Аспект-Пресс. С. 7-12.

Сравнительный регионализм. Россия - СНГ-Запад (под ред. А.С. Макарычева). 1997. Н. Новгород: Изд-во ННГУ. 345 с.

Туровский Р.Ф. 2015. Муниципальная политика. - Структурные транс- 
формации и развитие отечественных школ политологии (под ред. О.В. ГаманГолутвиной). М.: Аспект-Пресс. С. 216-242.

Хэмилтон М. 2013. Интегральный город. Эволюиионные интеллекты человеческого улья. М.: ИД ООО «Ориенталия». 685 с.

DAKHIN Andrei Vasil'evich, Dr. Sci. (Philos.), Professor, Head of the Chair of Philosophy and Political Science, Nizhny Novgorod Institute of Management - the Branch of Russian Presidential Academy of National Economy and Public Administration (RANEPA) (46 Gagarina Ave, Nizhny Novgorod, Russia, 603009; kaf-phyl@niu.ranepa.ru)

SOLONCHENKO Elizaveta Igorevna, postgraduate student at the Nizhny Novgorod Institute of Management - the Branch of Russian Presidential Academy of National Economy and Public Administration (RANEPA) (46 Gagarina Ave, Nizhny Novgorod, Russia, 603009; kaf-phyl@niu.ranepa.ru)

\section{CITY POLICY: A CRITICAL ANALYSIS OF THEORETICAL APPROACHES}

Abstract. The article suggests an analysis of contemporary theoretical approaches in the field of city policy studies. The authors analyze five approaches, both traditionally characteristic of political sciences, and reflecting a depoliticized vision of city life. The main attention is paid to the original concept of the integral city by $M$. Hamilton, which the authors assigned to the field of the depoliticized ones. The article shows that the concept of integral city is an attempt to combine a philosophical systemic understanding of the city and its empirical description. Consideration of the basic philosophical definitions and reasoning of the concept of integral city allows us to conclude that the philosophical platform integrates a person into the abstract system of holons. On the other hand, the integral city has a political mission: M. Hamilton considers it as a system of forcing people to execute the natural survival algorithm. The authors conclude that the critical rethinking of the basic philosophical axioms of the concept of an integral city is important, as well as the need for a more precise definition of the political management system, that this concept assumes.

Keywords: city policy, integral city, philosophy of city, social identity, bionic postmodernism 